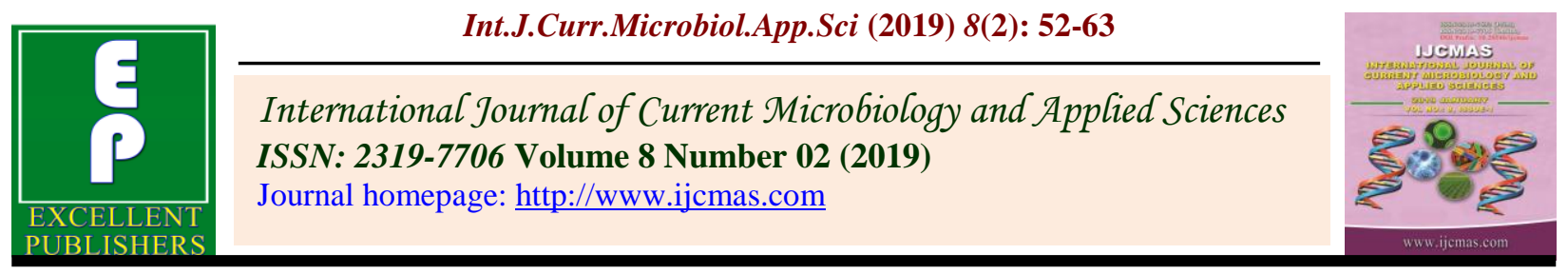

Original Research Article

https://doi.org/10.20546/ijcmas.2019.802.009

\title{
Mapping of Spatial Pattern of Micronutrients in Soils of Harda District of Madhya Pradesh through Geo-statistical Tool in Arc GIS Environment
}

\author{
Subhash $^{1 *}$, G.S. Tagore ${ }^{1}$, P.S. Kulhare ${ }^{1}$ and A.K. Shukla ${ }^{2}$ \\ ${ }^{1}$ Department of Soil Science \& Agricultural Chemistry JNKVV Jabalpur (M.P.), India \\ ${ }^{2}$ ICAR-Indian Institute of soil science, Bhopal (M.P), India \\ *Corresponding author
}

\section{A B S T R A C T}

Keywords

Geo-statistics,

Semi-variogram,

Micronutrients,

Harda, Ordinary

kriging, GIS

Article Info

Accepted:

04 January 2018

Available Online:

10 February 2019
In present study GPS based three hundred three surface $(0-15 \mathrm{~cm}$ depth) soil samples, were collected across the district. The $\mathrm{Zn}$, and Fe deficient in $79.54 \%$ and 7.92 percent soil samples and none of soil samples were found to be deficient in $\mathrm{Cu}, \mathrm{Mn}$ and $\mathrm{B}$. Soil $\mathrm{pH}$ showed significant and negative correlations with $\mathrm{Zn}, \mathrm{Cu}, \mathrm{Mn}$ and $\mathrm{Fe}$. The EC had positive and significant relationship with $\mathrm{OC}$ and $\mathrm{B}$ with $\mathrm{r}$ values of $0.163 * *$ and $0.168 * *$, respectively. The significant positive relationship of $\mathrm{OC}$ of soil with available hot watersoluble B showing value of $0.164 * *$. The micronutrients i.e. DTPA extractable $\mathrm{Zn}$ and $\mathrm{Cu}$, Fe and Mn showed significant positive relationship with each other. HWS B was also found positive and significantly related with $\mathrm{Fe}\left(\mathrm{r}=0.135^{*}\right)$. Geo-statistical suggested that the exponential models best fitted for, $\mathrm{Zn}$ and $\mathrm{B}$ while spherical models for $\mathrm{Cu}, \mathrm{Mn}, \mathrm{Fe}$. The nugget/sill ratios of semivariogram models for micronutrients were moderate. The having value were $0.78,0.49,0.44,0.42$ and 0.41 for $\mathrm{Mn}, \mathrm{Fe}, \mathrm{Zn}, \mathrm{B}$ and $\mathrm{Cu}$, respectively.

\section{Introduction}

Soil micronutrients play a major role to maintain soil health. Proportionate to primary and secondary nutrients, plants need a much smaller quantity of micronutrients. However, their importance is still great. A shortage of micronutrients can limit plant growth and crop yields. Too great a shortage could even because plant death, even with all other essential elements fully represented. An adequate attention is still necessary to pay in this area.

In Indian soils 49 percent soil are $\mathrm{Zn}$ deficient and over $57 \%$ soil samples are reported $\mathrm{Zn}$ deficient in Madhya Pradesh by Shukla and Tiwari (2016). In Madhya Pradesh, many soils are deficient in zinc, the highest percent in Alluvial soils (86\%) followed by mixed red and black soils (68\%), red and yellow soils (62\%), medium black soils (61\%), deep black soils $(35 \%)$ and skeletal soils $(31 \%)$ reported by Khamparia et al., (2009). Fageria et al., (2002) in their review of micronutrients in crop production, maintained that micronutrient deficiencies in crop plants are widespread worldwide. As many findings showed that micronutrients status in the soil is mostly a positively correlated with $\mathrm{OC}$ content but negatively correlated with soil $\mathrm{pH}$ 
(Dibabe et al., 2007). Determining soil variability and maintaining soil health is very much important for ecological modelling, environmental predictions, precise agriculture and management of natural resources (Hangsheng et al., 2005; Wang, 2009). Geostatistics is the strategy that considers spatial variance, location, estimation and distribution of samples. This study was done to investigate and map the spatial variability of micronutrients in the soil at different unsampled locations by using data at sampled locations.

\section{Materials and Methods}

\section{Description of study area}

Geographically, Harda district lies in between $21^{0} 53^{\prime}-22^{0} 36^{\prime}$ North latitude and $76^{\circ} 47^{\prime}$ $77^{\circ} 30^{\prime}$ 'East longitude with an area of 3330 $\mathrm{km}^{2}$. It is located in the Narmada river valley and the Narmada forms the district northern boundary.

Administratively, the district divided in six blocks, Rahatgaon, Harda, Khirkiya, Hundia, Sirrali and Timarani (Fig. 1). The district feels maximum temperature up to $47{ }^{0} \mathrm{C}$ and minimum up to $12{ }^{\circ} \mathrm{C}$ and an average annual rainfall of $1021.84 \mathrm{~mm}$. The district has varied physiographic; geology and diverse land use have resulted in diversity in soil development.

\section{Land use}

Land use map prepared by using Indian remote-sensing satellite-P6, linear imaging self-scanning satellite-III (IRS-P6, LISS-III). The satellite data has the characteristics of $23.5 \mathrm{~m}$ spatial resolution, four spectral channels green $(0.52 \mu \mathrm{m}-0.59 \mu \mathrm{m})$, red $(0.62$ $\mu \mathrm{m}-0.68 \mu \mathrm{m}), \operatorname{NIR}(0.77 \mu \mathrm{m}-0.86 \mu \mathrm{m})$, and SWIR $(1.55 \mu \mathrm{m}-1.70 \mu \mathrm{m})$ and five days' temporal resolution with $141 \mathrm{~km}$ swath. The major land-use/land-cover categories were identified and mapped (Fig. 1).

From the maps, it is evident that the major area is occupied $2082.20 \mathrm{sq} \mathrm{km}$, which was accounted to $62.52 \%$ by cultivated land. On interview basis of information obtained from every sampling site and local agriculture department, the soybean based cropping pattern is predominant viz., soybean-wheat, soybean-wheat-summer mungbean, soybeanchickpea and soybean-fallow. Sugarcane and horticultural crop/orchards-spices crop/ vegetables were also observed. The forest was classified in two categories; dense $20.0 \%$ $(666.0 \mathrm{sq} \mathrm{km})$ and $6.96 \%(231.90 \mathrm{sq} \mathrm{km})$.

Other land use categories are built-up (52.83 sq $\mathrm{km}$ ) which accounted by 1.59 percent represented to Harda city and some village's settlements. Water bodies were occupied $(68.25 \mathrm{sq} \mathrm{km})$ and $2.05 \%$ of TGA. The wasteland in four categories i.e., gullied/ravenous land $0.05 \%(1.82 \mathrm{sq} \mathrm{km})$, sandy area-riverine, $0.10 \% \quad(3.17 \mathrm{sq} \mathrm{km})$, dense scrub $1.28 \%$ (42.72 sq km) and open scrub $1.80 \%(59.89 \mathrm{sq} \mathrm{km})$ and minimum area covered by mining $0.01 \%(0.17 \mathrm{sq} \mathrm{km})$ of the total geographical area.

\section{Soil survey and sampling techniques}

Considering of cropping system and soil association maps, topography and heterogeneity of the soil type, the site for collecting of Jabalpur were divided GPS based three hundred three surface soil samples $(0-15 \mathrm{~cm})$ and field data were collected from farmer's field during the off season to avoid the effect of fertilization during crop cultivation. Soil samples were not taken from unusual areas like animal dung accumulation places, poorly drained and any other places that cannot give representative soil samples. 


\section{Soil analysis}

The soil samples were air dried and crushed with wooden pestle and mortar and sieved through $2 \mathrm{~mm}$ sieve was determined using the $\mathrm{pH}$ meter with a soil: water ratio of 1: 2.5 and supernatant of same was used for electrical conductivity determination with the help of conductivity-meter. The organic carbon in soil was determined using Nelson and Sommers (1982) and calcium carbonate content in soils carried out using rapid back titration described method as Jackson (1973). Available micronutrients were extracted with diethylene triamine pentaacetic acid (DTPA), were determined with Flame Atomic Absorption Spectrometry as described by Lindsay and Norvell (1978). Hot water soluble boron in soil was analyzed by Azomethine- $\mathrm{H}$ method as outlined by Berger and Truog (1939).

NI calculated as per formula suggested by Parker et al., (1951) and classified this index as low (<1.67), medium (1.67 to 2.33) and high $(>2.33) . \mathrm{NI}=[(\mathrm{Nl} \times 1)+(\mathrm{Nm} \times 2)+(\mathrm{Nh}$ x 3$)] / \mathrm{Nt}$,

Where: $\mathrm{Nl}, \mathrm{Nm}$ and $\mathrm{Nh}$ are the number of soil samples falling in low, medium and high categories for nutrient status and are given weightage of 1,2 and 3, respectively. $\mathrm{Nt}$ is the total number of samples.

\section{Statistical and geo-statistical analysis}

Geo-statistics is a powerful tool for determining the spatial variability (Jian-Bing et al., 2008). ArcGIS 10.1 software was used for statistical and geo-statistical analysis of the data. Semivariogram analysis was done to calculate the nugget to sill ratio, which indicates the degree of spatial dependence by using uniform interval to establish the range of spatiality. According to criteria given by Attar et al., (2012) spatial dependence is classified in to weak (ratio $>75 \%$ ), moderate (ratio 25-75\%) and strongly spatial dependent (ratio $<25 \%$ ). Because Kriging assumes the normal distribution for each estimated variable, it is necessary to check whether the available contents of micronutrients $(\mathrm{Zn}, \mathrm{Cu}$, $\mathrm{Fe}, \mathrm{Mn}$ and $\mathrm{B}$ ) in soil samples are approximately normally distributed or not. A normal distribution was estimating based on skewness values and the variable datasets having a skewness ranged between -1 to 1 were considered normally distributed (Ortiz et al., 2010). For non-datasets, a logarithmic transformation was performed to achieve a normal distribution for use in the next step of the statistical analysis.

Among the geostatistical techniques, Kriging is a linear interpolation procedure that provides a best linear unbiased estimation for quantities, which vary in space. The semivariogram analyses were carried out before application of ordinary kriging interpolation as the semi-variogram model determines the interpolation function (Goovaerts, 1997) as given below.

$y(h)=\frac{1}{2 N(h)} \sum_{i=1}^{N N(h)}\left[\mathrm{z}\left(\mathrm{x}_{\mathrm{i}}\right)-\mathrm{z}\left(\mathrm{x}_{\mathrm{i}}+\mathrm{h}\right)\right]^{\mathrm{z}}$,

Where $\mathrm{N}(\mathrm{h})$ is the total number of data pairs separated by a distance $\mathrm{h}, \mathrm{Z}$ represents the measured value for soil property, and $\mathrm{x}$ is the position of soil samples.

Several standard models are available to fit the different semi-variogram functions were evaluated to select the best fit with the data, e.g., spherical, exponential, Gaussian, linear and power models (Wang, 1999).

The spherical function is:

$$
\begin{aligned}
& y(h)=C_{0}+C\left[\frac{3 h}{2 a}-\frac{1}{2}\left(\frac{h}{a}\right)^{3}\right] \quad 0<\mathrm{h} \leq \mathrm{a} \\
& y(h)=C_{0}+C \quad \mathrm{~h}>\mathrm{a}
\end{aligned}
$$


Where $\mathrm{C}_{0}$ is the nugget variance $(\mathrm{h}=0), \mathrm{C}$ is the structural variance and the spatial range.

Exponential model was fitted to the empirical semivariograms. The exponential model that fitted to experimental semivariograms is defined below (Burgess and Webster, 1980) as:

$y(h)=C_{0}+C_{1}\left[1-\exp \left(\frac{h}{a}\right)\right]$

Where, $\mathrm{C}_{0}$ is the nugget, $\mathrm{C}_{1}$ is the partial sill, and $\mathrm{a}$ is the range of spatial dependence to reach the sill $\left(\mathrm{C}_{0}+\mathrm{C}_{1}\right)$. The nugget/sill ratio, i.e. $\mathrm{C}_{0} /\left(\mathrm{C}_{0}+\mathrm{C}_{1}\right)$ and the range are the parameters which characterize the spatial structure of a soil property. The range defines the distance over which the soil property values are correlated with each other. A low valueofC $\mathrm{C}_{0} /\left(\mathrm{C}_{0}+\mathrm{C}_{1}\right)$ and a high range generally indicates that high precision of the property can be obtained by kriging. The nugget/sill ratio was used as the criterion to classify the spatial dependence of variables. Ratio values lower than or equal to 0.25 were considered to have strong spatial dependence, whereas values between 0.25 and 0.75 indicate moderate dependence and those greater than 0.75 show weak spatial dependence (Cambardella et al., 1994).

Prediction accuracy of semivariogram models was evaluated by mean square error (MSE). Among two evaluation indices used in this study, mean absolute error (MAE) and measure the accuracy of prediction, whereas goodness of prediction (G) measure the effectiveness of prediction.

$\mathrm{MAE}=\frac{1}{N} \sum_{\mathrm{i}=1}^{N}\left[\left|\mathrm{z}\left(\mathrm{x}_{\mathrm{i}}\right)-\mathrm{z}\left(\mathrm{x}_{\mathrm{i}}\right)\right|\right]$

Where, $\mathrm{n}$ is the number of observation for each case, $\mathrm{z}(\mathrm{xi}, \mathrm{yi})$ is the observed soil parameter, $\mathrm{z}^{*}(\mathrm{xi}, \mathrm{yi})$ is the estimated soil parameter, and (xi, yi) are sampling coordinates. Using the geospatial parameters of the best fitted exponential semivariogram model, interpolation was made through ordinary kriging (Goovaerts, 1997).

The MAE measure, however, does not reveal the magnitude of error that might occur at any point and hence MSE was calculated,

MSE $=\frac{1}{N} \sum_{i=1}^{N}\left[\mathrm{z}\left(\mathrm{x}_{\mathrm{i}}\right)-\hat{\mathrm{z}}\left(\mathrm{x}_{\mathrm{i}}\right){ }^{2}\right.$

Where $\mathrm{z}$ is the sample means If $\mathrm{G}=100$, it indicates perfect prediction, while negative values indicate that the predictions are less reliable than using sample mean as the predictors

$G=\left(1-\frac{\sum_{i=1}^{N}\left[\mathrm{z}\left(\mathrm{x}_{\mathrm{i}}\right)-\hat{\mathrm{z}}\left(\mathrm{x}_{\mathrm{i}}\right)\right]^{2}}{\sum_{\mathrm{i}=1}^{N}\left[\mathrm{z}\left(\mathrm{x}_{\mathrm{i}}\right)-\overline{\mathrm{z}}\right]^{2}}\right) \times 100$

Squaring the difference at any point gives an indication of the magnitude, e.g. small MSE values indicate more accurate estimation, point-by-point. The $\mathrm{G}$ measure gives an indication of how effective a prediction might be, relative to that which could have been derived from using the sample mean alone (Agterberg, 1984).

\section{Results and Discussion}

\section{Soil characteristics}

The descriptive statistics on soil characteristics are presented in table 2 showed the $\mathrm{pH}, \mathrm{EC}, \mathrm{OC}$ and $\mathrm{CaCO}_{3}$ varied from 6.42$8.90,0.09-0.98 \mathrm{dSm}^{-1}, 2.35-10.16 \mathrm{~g} \mathrm{~kg}^{-1}$ and $5.0-115 \mathrm{~g} \mathrm{~kg}^{-1}$ with the mean values of 7.61 , $0.20 \mathrm{dSm}^{-1}, 5.32 \mathrm{~g} \mathrm{~kg}^{-1}$ and $37.35 \mathrm{~g} \mathrm{~kg}^{-1}$, respectively. The $\mathrm{Zn}, \mathrm{Cu}, \mathrm{Fe}, \mathrm{Mn}$ and $\mathrm{B}$ varied from 0.02-2.50, 0.78-7.84, 1.91-35.34, 2.93-35.18 and 0.5-2.9 $\mathrm{mg} \mathrm{kg}^{-1}$ with mean 
values of $0.49,2.16,10.05,18.19$ and 1.33 $\mathrm{mg} \mathrm{kg}^{-1}$, respectively in the district as a whole (Table 1).

Considering CV $<10 \%$ as low, 10 to $100 \%$ as moderate, $>100 \%$ as high variability, result revealed that the $\mathrm{CaCO}_{3}$ had the largest variation $(\mathrm{CV}=83.40$ percent $)$ followed by $\mathrm{EC}(\mathrm{CV}=60.00$ percent $), \mathrm{OC}(\mathrm{CV}=24.06)$ and $\mathrm{pH}$ had least variability $(\mathrm{CV}=6.70$ percent). Among the micronutrients, the $\mathrm{Zn}$ was found to be highly variable $(\mathrm{CV}=77.55$ percent), followed by $\mathrm{Fe}(\mathrm{CV}=60.30$ percent $)$, $\mathrm{Cu}(\mathrm{CV}=54.17$ percent $)$ and $\mathrm{Mn}(\mathrm{CV}=48.16$ percent) while the hot water soluble B only 39.85 percent variability.

The $\mathrm{pH}$ had low variability and all other soil properties showed moderate variability. The micronutrients with CV ranged from 39.8577.55 per cent. Further, it was observed from the table 2 that the skewness coefficients of the data set ranged from -0.45 to 3.70 revealed the value of skewness and kurtosis was higher for $\mathrm{EC}, \mathrm{CaCO}_{3}$ and $\mathrm{Zn}, \mathrm{Cu}, \mathrm{Fe}$, $\mathrm{Mn}$ and B. Hence, these variables are largely deviated from normal distribution.

The $\mathrm{Zn}$ and $\mathrm{Fe}$ deficiency was observed in $79.54 \%$ and $7.92 \%$ soil samples and none of soil samples were found deficient in $\mathrm{Cu}, \mathrm{Mn}$ and $\mathrm{B}$. The percent soil samples were found medium in respect of $\mathrm{Zn}, \mathrm{Fe}, \mathrm{Mn}$ and $\mathrm{B}$ by $15.18,46.53,2.31$ and $34.32 \%$. The $5.28 \%$, $100 \%, 45.54 \%, 97.69 \%$ and $65.68 \%$ soil samples were fall in high in case of $\mathrm{Zn}, \mathrm{Cu}$, $\mathrm{Fe}, \mathrm{Mn}$ and $\mathrm{B}$, respectively and kriged maps the spatial analysis results in the form of maps were showed in figure $\mathrm{Zn}(3 \mathrm{a}), \mathrm{Cu}(3 \mathrm{~b}), \mathrm{Fe}(3 \mathrm{c})$, Mn (3d) and B (3e) (Table 3). The kriged map of spatial variability of soil nutrient could be used as a basis for consideration in variable rate fertilization, especially for $\mathrm{Zn}$ and $\mathrm{Fe}$ in order to supply the optimum requirements for plant growth that can be optimized crop production. In case of $\mathrm{Cu}$, all soil samples were in high category and none of soil samples were found to be deficient and medium category. Data further indicate that the NI value was found to be low 1.26 , for $\mathrm{Zn}$, respectively and in whole district, high nutrient index value of 2.38, 2.66, 2.98 and 3.00 for $\mathrm{Fe}, \mathrm{B}, \mathrm{Mn}$ and $\mathrm{Cu}$, respectively.

\section{Correlation matrix}

Pearson's' correlation matrix data showed that the $\mathrm{pH}$ of soil had significant negative relationship with $\mathrm{Zn}, \mathrm{Cu}, \mathrm{Fe}$ and $\mathrm{Mn}$. The EC had positive and significant relationship with $\mathrm{OC}$ and $\mathrm{B}$ with $\mathrm{r}$ values of $0.163^{* *}$ and $0.168^{* *}$, respectively. The significant positive relationship of OC of soil with available hot water soluble $\mathrm{B}$ was observed by showing values of $0.164 * *$ respectively. Micronutrient showed significantly positively related with each other. Results were supported by Katyal and Sharma (1991, Rajakumar et al., (1996), Chinchmalatpure et al., (2006) (Table 4).

\section{Spatial variability assessment using GIS}

The spherical and exponential were best fitted models for with low MSE values. The nugget (an indication of micro-variability) was highest for $\mathrm{Zn}, \mathrm{Mn}$, which is ascribed to the fact that the selected sampling distance could not capture the spatial dependence well. The moderate spatial dependence showed values table 5 with the having nugget/sill ratio values $0.78,0.49,0.44,0.42$ and 0.41 for $\mathrm{Mn}, \mathrm{Fe}$, $\mathrm{Zn}, \mathrm{B}$ and $\mathrm{Cu}$ respectively moderate spatial dependence.

This is attributed to inherent soil properties (such as soil pH, EC, SOC and soil mineralogy) as well as management factors including fertilization. Samples separated by distances lower than the range are spatially related, whereas those separated by a distance greater than the range are considered not to be spatially related. A large range indicates the 
value of measured soil property to be influenced by natural and anthropogenic ranges (Lopez-Granados et al., 2002). The different range soils might be due to combined effect of parent material, climate and adoption of different land management. Several authors reported range values of 2.5$9.1 \mathrm{~km}$ for $\mathrm{Zn}, 3.30-28 \mathrm{~km}$ for $\mathrm{Cu}$ (Behera et al., 2012), 0.7-66 km for Mn and 2.7-5.2 km for Fe (Behera and Shukla, 2014) in some acid soils of India. Information on the range in semi-variogram of $\mathrm{Zn}, \mathrm{Cu}, \mathrm{Mn} \mathrm{Fe}$ and $\mathrm{B}$ acts as a guide in future soil sampling designs in similar areas. The sampling interval should be less than half the semivariogram range (Kerry and Oliver, 2004). It is therefore recommended that for ensuing studies aimed at characterizing spatial dependency of $\mathrm{Zn}$, $\mathrm{Cu}, \mathrm{Mn} \mathrm{Fe}$ and $\mathrm{B}$ in similar areas, soil sampling should be done at distances shorter than the range found in this study.

Cultivation of high yielding varieties of different crops coupled with non-inclusion of micronutrients in fertilizer scheduling also contributed to spatial variability of micronutrients (Shukla et al., 2015).

Table.1 Critical limits of soil characteristics

\begin{tabular}{|l|l|l|l|l|l|}
\hline Parameters & Zn & Cu & Fe & Mn & B \\
\hline Low & $<0.60$ & $<0.20$ & $<4.50$ & $<1.0$ & $<0.50$ \\
\hline Medium & $0.61-1.20$ & $0.21-0.40$ & $4.51-9.0$ & $1.0-4.0$ & $0.51-1.00$ \\
\hline High & $>1.20$ & $>0.40$ & $>9.0$ & $>4.0$ & $>1.00$ \\
\hline
\end{tabular}

Table.2 Statistical summary of soil characteristics $(n=303)$

\begin{tabular}{|l|c|c|c|c|c|c|c|}
\hline \multicolumn{1}{|c|}{ Soil characteristics } & Minimum & Maximum & Mean & S. D. & Skewness & Kurtosis & $\begin{array}{c}\text { CV } \\
(\boldsymbol{\%})\end{array}$ \\
\hline pH & 6.40 & 8.90 & 7.61 & 0.51 & -0.45 & -0.48 & 6.70 \\
\hline EC dSm & & & & & & & \\
\hline SOC g kg & 0.09 & 0.98 & 0.20 & 0.12 & 3.70 & 17.39 & 60.00 \\
\hline CaCO $^{-1} \mathbf{g ~ k g}^{-1}$ & 2.35 & 10.16 & 5.32 & 1.28 & 0.13 & 0.26 & 24.06 \\
\hline DTPA-Zn mg kg-1 & 5.00 & 115.00 & 37.35 & 31.15 & 0.83 & -0.45 & 83.40 \\
\hline DTPA-Cu mg kg-1 & 0.02 & 2.50 & 0.49 & 0.38 & 2.84 & 9.97 & 77.55 \\
\hline DTPA-Fe mg kg-1 & 0.78 & 7.84 & 2.16 & 1.17 & 2.13 & 5.72 & 54.17 \\
\hline DTPA-Mn mg kg-1 & 1.91 & 35.34 & 10.05 & 6.06 & 1.93 & 4.29 & 60.30 \\
\hline HWS-B mg kg-1 & 2.93 & 35.18 & 18.19 & 8.76 & 0.15 & -1.27 & 48.16 \\
\hline
\end{tabular}

Table.3 Status of micronutrient in soil of Harda district $(n=303)$

\begin{tabular}{|c|c|c|c|c|c|}
\hline \multirow{2}{*}{ Micronutrients } & \multicolumn{3}{|c|}{ Percent samples } & \multirow{2}{*}{ NI } & \multirow{2}{*}{ NI class } \\
\cline { 2 - 4 } & Low & Medium & High & & \\
\hline Zn & 79.54 & 15.18 & 5.28 & 1.26 & Low \\
\hline Cu & 0.00 & 0.00 & 100 & 3.00 & High \\
\hline Fe & 7.92 & 46.53 & 45.54 & 2.38 & High \\
\hline Mn & 0.00 & 2.31 & 97.69 & 2.98 & High \\
\hline HWS-B & 0.00 & 34.32 & 65.68 & 2.66 & High \\
\hline
\end{tabular}


Table.4 Pearson's correlation coefficients

\begin{tabular}{|c|c|c|c|c|c|c|c|c|}
\hline \multirow[t]{2}{*}{ parameters } & \multicolumn{4}{|c|}{ Physico-chemical properties } & \multicolumn{4}{|c|}{ Micro nutrients } \\
\hline & pH & EC & OC & $\mathrm{CaCO}_{3}$ & $\mathbf{Z n}$ & $\mathbf{C u}$ & $\mathbf{F e}$ & Mn \\
\hline EC & $0.153 * *$ & 1 & & & & & & \\
\hline OC & $0.138^{*}$ & $0.163 * *$ & 1 & & & & & \\
\hline $\mathrm{CaCO}_{3}$ & 0.017 & 0.059 & -0.013 & 1 & & & & \\
\hline Zn & $-0.144 *$ & 0.024 & 0.087 & 0.049 & 1 & & & \\
\hline $\mathbf{C u}$ & $-0.251 * *$ & -0.007 & 0.071 & -0.076 & $0.317 * *$ & 1 & & \\
\hline $\mathbf{F e}$ & $-0.476 * *$ & -0.082 & 0.058 & 0.065 & $0.385 * *$ & $0.611 * *$ & 1 & \\
\hline Mn & $-0.473 * *$ & 0.001 & 0.013 & 0.011 & $0.263 * *$ & $0.453 * *$ & $0.663 * *$ & 1 \\
\hline HWS-B & -0.024 & $0.168 * *$ & $0.164 * *$ & 0.077 & 0.033 & -0.031 & $0.135^{*}$ & 0.026 \\
\hline
\end{tabular}

Table.5 Theoretical model parameters fitted to experimental semi-variograms for the studied micronutrients

\begin{tabular}{|c|l|l|c|c|c|c|c|c|}
\hline Micronutrients & Model & Range(m) & $\begin{array}{c}\text { Nugget } \\
\left(\mathbf{C}_{\mathbf{0}}\right)\end{array}$ & $\begin{array}{c}\text { Partial Sill } \\
\left(\mathbf{C}_{\mathbf{1}}\right)\end{array}$ & $\begin{array}{c}\text { Sill } \\
\left(\mathbf{C}_{\mathbf{0}}+\mathbf{C}_{\mathbf{1}}\right)\end{array}$ & Nugget/Sill & MAE & $\mathbf{G}$ \\
\hline $\mathbf{Z n}$ & Exponential & 17622.70 & 0.22 & 0.28 & 0.49 & 0.44 & 0.00 & 10.59 \\
\hline $\mathbf{F e}$ & Spherical & 3960.50 & 0.12 & 0.12 & 0.24 & 0.49 & 0.00 & 27.25 \\
\hline $\mathbf{C u}$ & Spherical & 3772.74 & 0.08 & 0.11 & 0.19 & 0.41 & 0.12 & 33.56 \\
\hline $\mathbf{M n}$ & Spherical & 4019.87 & 0.22 & 0.06 & 0.28 & 0.78 & 0.59 & 9.14 \\
\hline $\mathbf{B}$ & Exponential & 8974.11 & 0.07 & 0.10 & 0.17 & 0.42 & 0.01 & 28.90 \\
\hline
\end{tabular}

Figure.1 Location map of study area

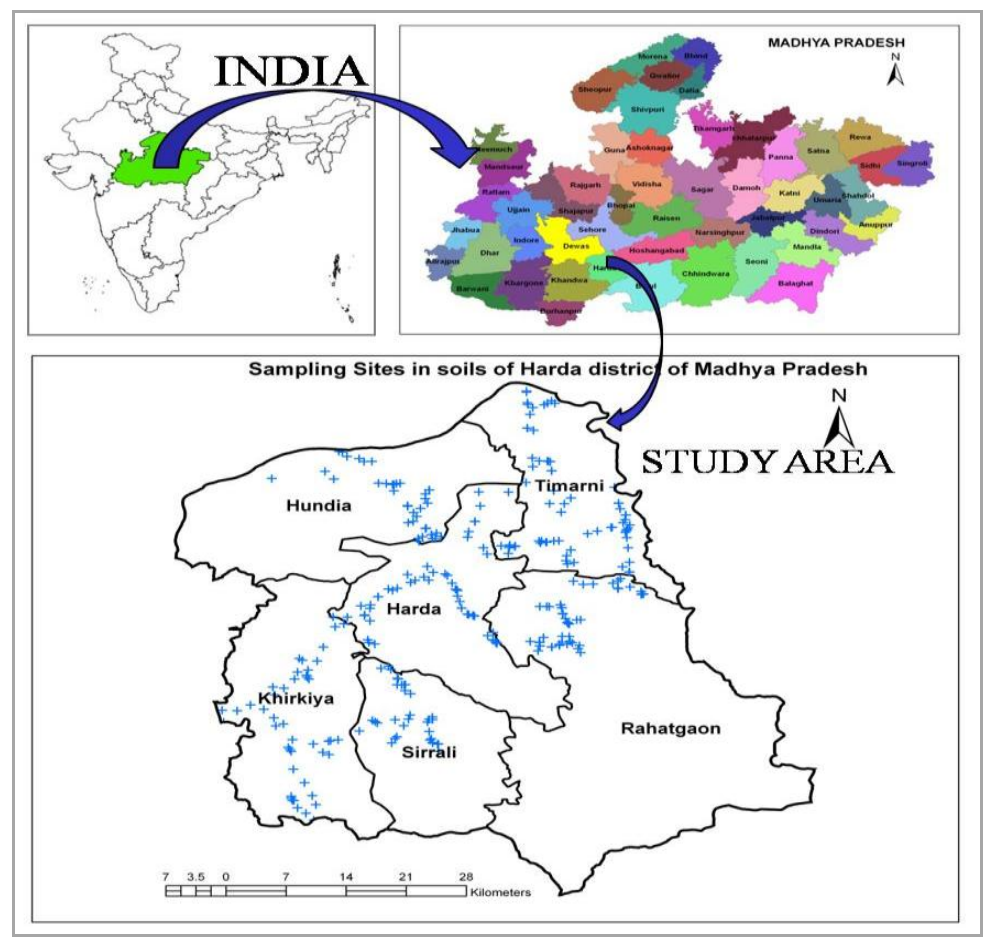



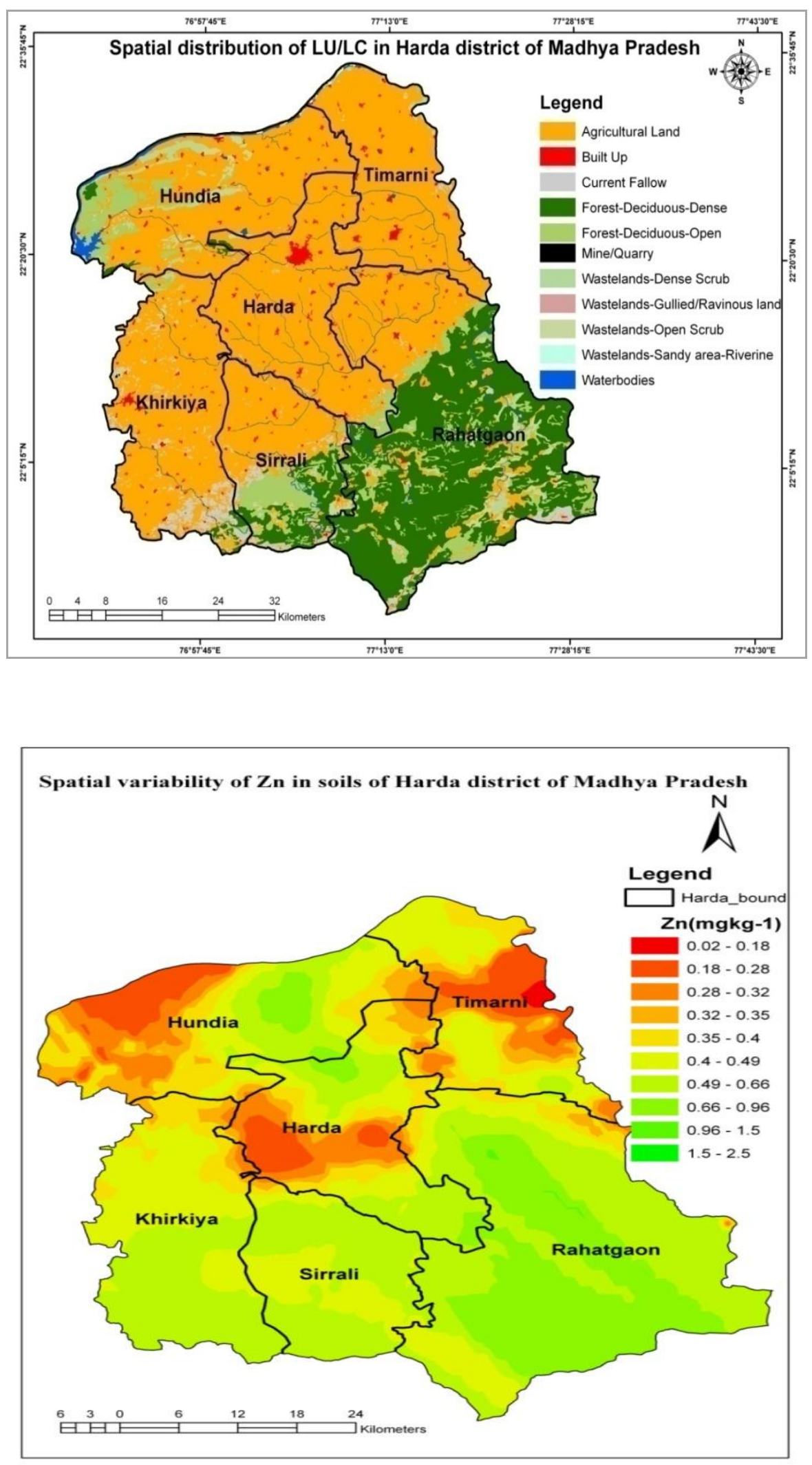

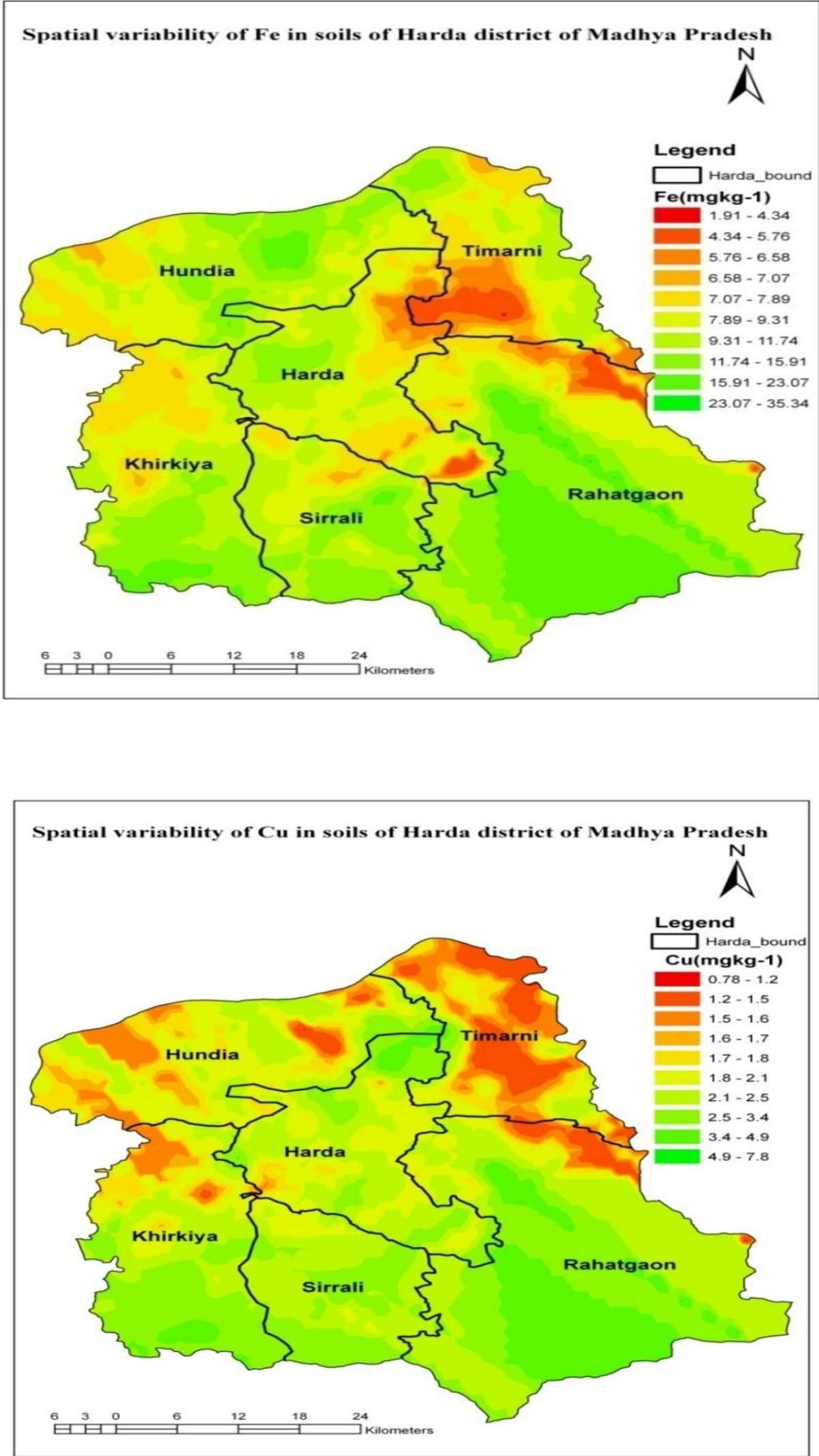

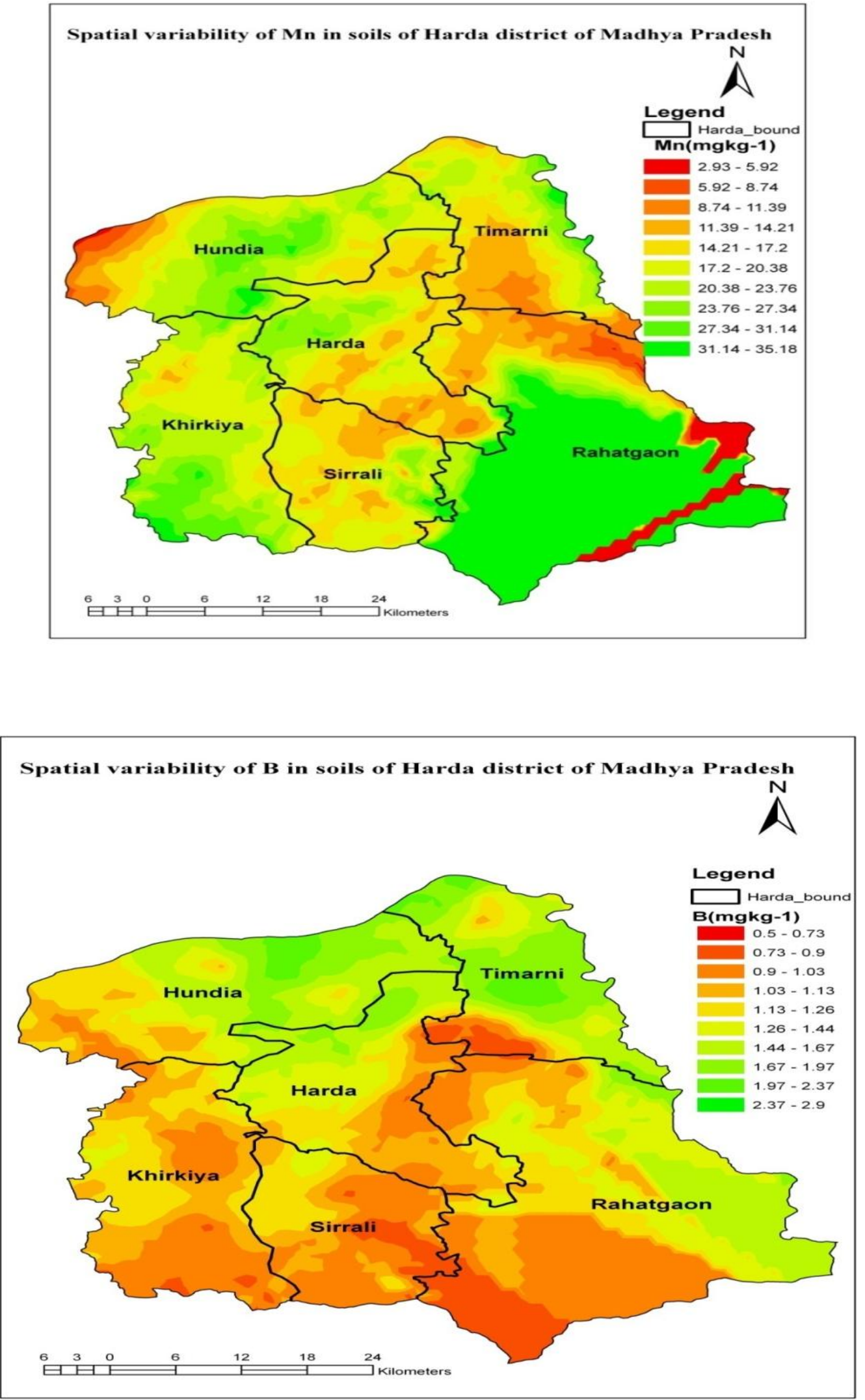
It is concluded that the soils of Harda district were found neutral to alkaline in soil reaction, safe in electrical conductivity, low to medium in organic carbon content and non-calcareous to slightly calcareous in nature. The result of this study suggested that the exponential models best fitted for, $\mathrm{Zn}$ and $\mathrm{B}$ while spherical model for $\mathrm{Cu}, \mathrm{Mn}, \mathrm{Fe}$. The nugget/sill ratios of semivariogram models for $\mathrm{Zn}, \mathrm{Fe}, \mathrm{Cu}, \mathrm{Mn}$ and $\mathrm{B}$ falls between $38 \%$ and $75 \%$, which exhibit moderate spatial dependency. Correlation results also that soil $\mathrm{pH}$ had a negative significant relationship with available micronutrients. OC exhibited significant positive correlation with micronutrients advised to apply organic matter to their field to supply nutrients. The spatial variability map of soil characteristics showed that the micronutrient mainly $\mathrm{Zn}$ and $\mathrm{Fe}$ are deficient so far the $\mathrm{Zn}$ and Fe fertilizers in the area to be recommended for increasing productivity and sustainability.

\section{Acknowledgment}

The authors of manuscript are highly thankful to Head, Department of Soil Science, College of Agriculture, JNKVV, Jabalpur, Madhya Pradesh for providing necessary facility to conduct research.

\section{References}

Agterberg FP.1984. Trend surface analysis in spatial statistics and models (eds Gaile GL and Willmott CJ.), Reidel, Dordrecht, The Netherlands: 147-171.

Berger KC and Truog E. 1939. Boron determination in soils and plants. Ind. Eng. Chem. Anal. Ed. 11:540-545.

Burgess, T.M., Webster, R.R., 1980. Optimal interpretation and isarithmic mapping of soil properties: I. The variogram and punctual kriging. J. Soil Sci. 31, 315-331.

Cambardella, C.A., Moorman, T.B., Novak,
J.M., Parkin, T.B., Karlen, D.L., Turco, R.F., Konopka, A.E., 1994. Field scale variability of soil properties in central Iowa soils. Soil Sci. Soc. Am. J. 58, 1501-1511.

Chinchmalatpure AR, Knayak A, Gururajarao MK, Khandelwal, Munsml HY and Tyagi NK. 2006. Spatial variability analysis of some soil properties in the irrigation block of Sardar Sarovar canal command of Gujarat Celurai. Soil Salinity Research Institute, Regional Research Station Anand India Agropedology. 16(2):63-70.

Davis BM. 1987. Uses and abuses of crossvalidation in geo-statistics Math. Geol. 19: 241-248. 33.

Fageria NK, Baligar VC and Clark RB. 2002. Micronutrients in crop production, Adv. Agron. 77:185-268.

Goovaerts P. 1999. Geo-statistics in soil science: state-of-the-art and perspectives. Geoderma 89:1-45.

Hengl T, Heuvelink GBM and Stein A. 2004. A generic framework for spatial prediction of soil variables based on regression-kriging. Geoderma. 120:75-93.

Jackson ML. 1973.Soil chemical analysis prentice hall of India Private Limited New Delhi.

Jian-Bing W, Du-Ning X, Hui Z and Yi-Kun F. 2008, Spatial variability of soil properties in relation to land use and topography in a typical small watershed of the black soil region, northeastern China. Environ. Geol. 53: 1663-1672.

Katyal JC and Sharma BD. 1991. DTPAextractable and total $\mathrm{Fe}, \mathrm{Cu}, \mathrm{Mn}$ and $\mathrm{Fe}$ in Indian soils and their association with some soil properties. Geoderma. 49: 165-179.

Khamparia RS, Sharma BL, Singh MV and Sharma GD. 2009. For decades of research in micro, secondary nutrient 
and pollutant element in soil and plants, research bulletin 49:30-31.

Lindsay WL and Norvell WA. 1978. Development of a DTPA soil test for $\mathrm{Zn}, \mathrm{Fe}, \mathrm{Mn}$ and $\mathrm{Cu}$. Soil Sci. Soc. Am. J. 42: 421-428.

Ortiz BV, Perry C, Goovaerts P, Vellidis G and Sullivan D. 2010. Geostatistical modeling of the spatial variability and risk areas of Southern root-knot nematodes in relation to soil properties. Geoderma. 156: 243-252.

Parker FW, Nelson WL, Winter Eric and Miller LE. 1951. The broad interpretation of soil test information. Agronomy J. 43: 105-112.

Sauer TJ, Cambardella CA and Meek DW. 2006. Spatial variation of soil properties relating to vegetation changes Plant and Soil. 280:1-5.

Shukla AK and Tiwari PK. 2014. Micro and secondary nutrients and pollutant elements research in India in soils and plants. Coordinator Report-AICRP Micro and secondary nutrients and pollutant elements in soils and plants. IISS, Bhopal pp.28.

Shukla, A.K., Malik, R.S., Tiwari, P.K. Prakash, C., Behera, S.K., Yadav, H., Narwal, R.P. 2015. Status of micronutrient deficiencies in soils of Haryana: impact on crop productivity and human health. Ind. J. Fert. 11, 1627.

Wang YQ, Zhang XC, Zhang JL and Li SJ. 2009. Spatial variability of soil organic carbon in a watershed on the Loess Plateau. Pedosphere. 19: 486495.

Warrick AW, Myers DE and Nielsen DR. 1986. Geo-statistical methods applied to soil science. In: Methods of Soil Analysis, Part 1. Physical and Mineralogical Methods. Agronomy Monograph. 9(2): 53-82.

Webster, R., Oliver, M.A., 1990. Statistical Methods in Soil and Land Resource Survey. Oxford University Press, London.

\section{How to cite this article:}

Subhash, G.S. Tagore, P.S. Kulhare and Shukla, A.K. 2019. Mapping of Spatial Pattern of Micronutrients in Soils of Harda District of Madhya Pradesh through Geo-statistical Tool in Arc GIS Environment. Int.J.Curr.Microbiol.App.Sci. 8(02): 52-63.

doi: https://doi.org/10.20546/ijcmas.2019.802.009 